\title{
The Importance of Improving Youths' Attitudes Toward Science (TAS): A Validation of a Short Form Assessment of Attitudes in Science Constructs for Fourth Grade (AASC-4)
}

\author{
Sebastian Diaz', Ashley Roseno², Virginia Stage ${ }^{2}$, Shawn Moore², Allender Lynch², Dan Dickerson², and Melani W. \\ Duffrin ${ }^{3}$ \\ ${ }^{1}$ Ohio University, Athens, $\mathrm{OH}$; ${ }^{2}$ East Carolina University, Greenvile, NC; ${ }^{3}$ Northern Illinois University, DeKalb, IL. \\ Keywords: Attitudes, STEM Education, Attitudinal Survey, Science Education, Health Education, NIH, SEPA \\ Publication Date: December 3, 2018
}

DOI: https://doi.org/10.15695/jstem/v1i1.25

\begin{abstract}
If children have opportunities to develop positive attitudes toward learning science, the pipeline to science careers can be maintained and enhanced. This article describes the development and validation of a short form, 24-item, Assessment of Attitudes in Science Constructs for Fourth Grade (AASC-4) for utilization in future research aimed at improving youths' Attitudes Toward Science (ATS). A researcher developed long form, 50-item AASC-4 was administered in an intervention and comparison, pre- and post-implementation science education study $(\mathrm{n}=1,117)$. Exploratory factor analysis was conducted to reduce the original 50-item AASC-4 to the current 24-item form. The current AASC-4 included 24 questions, and eight constructs. Reliability measures of the short-form AASC-4 improved reliability for Fear of Failure on Course from 0.200 to 0.694, Value of Science from 0.478 to 0.779, Attitudes of Family (Parents) toward Science from 0.706 to 0.754 , and Perception of the Science Teacher from 0.700 to 0.791 . Utilization of the validated constructs within the short-form AASC-4 may help researchers and educators identify science education intervention features that have positive impact on youths' ATS.
\end{abstract}

\section{INTRODUCTION}

Defining Attitudes. Attitudes are guided by a person's preexisting knowledge and belief about an issue. Attitudes guide decisions that set the precedent for carrying out actions, whether positive or negative (Barmby et al., 2008; Osborne et al., 2003). Cognitive, affective, and behavioral aspects are measured when assessing attitudes. The cognitive aspect of attitude includes a person's knowledge or beliefs about a domain, while the affective aspect includes a person's feelings or beliefs about an object. The behavioral aspect includes both intention and actual behavior and is somewhat dependent upon the cognitive and affective aspects (Young, 1998). Science attitudes, however, can be further defined as scientific attitudes or Attitudes Toward Science (ATS), two distinct constructs that may compromise science attitudinal research when both are assessed in the same instrument. Scientific attitudes assess scientific thinking and are complex and more cognitive in nature. Attitudes Toward Science (ATS) are a person's feelings, beliefs, or values about science (Barmby et al., 2008; Blalock et al., 2008; Krynowsky, 1988; Osborne et al., 2003;). It is important, therefore that researchers clarify which type of science attitudinal assessment (scientific attitudes or ATS) is of interest to them before developing a respective instrument (Barmby et al., 2008; Osborne et al.,
2003). This study will discuss development of the AACS-4 (4th Grade) instrument intended to measure ATS.

Attitudes Toward Sciences. Attitudes Toward Science (ATS) does not consist of a singular construct, rather a compilation of many subscales each contributing in its own manner. Since 1975, researchers have identified numerous constructs that comprise ATS (Osborne et al., 2003). Researchers identified eight predominant construct themes from the attitudes literature for the purpose of developing the AACS-4. The constructs included: (a) Perception of the Science Teacher; (b) Self-esteem at Science; (c) Fear of Failure on Course; (d) Value of Science; (e) Enjoyment of Science; (f) Motivation toward Science; (g) Attitudes of Friends and Peers toward Science, and; (h) Attitudes of Family (Parents) toward Science. Many of these constructs are considered interrelated and can greatly impact student performance (George, 2000; Kind et al., 2007; Osborne et al., 2003;).

The construct (a) Perception of the Science Teacher, has been found to be one of the greatest influences on student attitudes because of teachers' influence on the learning environment. While there are some variables that cannot be controlled such as teacher age and student gender, others 
like teacher reinforcement and praise of students can be controlled (George, 2000). Teachers should be encouraged to create positive experiences for students to promote engagement (Christidou, 2011; Tosun, 2000; Yilmaz-Tuzun, 2008). Furthermore, teacher attitudes toward the content being taught can greatly impact student learning. Teachers harboring negative attitudes toward a particular topic can be transferred to students, thus leading to changes in their attitudes (Christidou, 2011; Palmer, 2002; Tosun, 2000; Yilmaz-Tuzun, 2008).

Research has shown that confidence or the construct named (b) Self-esteem at Science is a predictor of students' persistence in science and science achievement (Fouad and Smith, 1996; Matterm and Schau, 2002). Moreover, self-confidence has been found to be a greater predictor of coursework choices than performance measures suggesting students must not only perform well in science, but also maintain high self-confidence in their ability to succeed in science (Marsh and Yeung, 1997). Therefore, it could be considered essential to increase student self-confidence to ensure continued pursuit of science courses throughout their education. It is also important to note how constructs can become interrelated or impactful on other constructs. For instance, the teacher or (a) Perception of the Science Teacher may also impact confidence or (b) Self-esteem at Science.

A notable interrelationship between constructs is the lack of (b) Self-esteem at Science has been associated with (c) Fear of Failure on Course, which could ultimately result in negative ATS (Elliot and Sheldon, 1997; Germann, 1988). Even in the most ideal environments students affected by the construct (c) Fear of Failure on Course, could experience painful consequences of unsuccessful attempts at science-related tasks. These experiences may result in avoidance of such tasks to ensure failure will not occur (Conroy et al., 2003). Fear of failure could also affect how students value science.

The construct (d) Value of Science, refers to the value students place on science in their daily lives for future careers. If students are harboring negative attitudes as a result of construct (c) Fear of Failure on Course, they are less likely to visualize the usefulness of science to their future pursuits. Interestingly, researchers have found a decrease in student perception of science value as they age to young adulthood (Yager and Penik, 1986). However, positive ATS have been found to pique and sustain student interest resulting in positive attitudes toward science and science-related careers (Pell and Jarvis, 2001).

Student (e) Enjoyment of Science is associated with engagement and preference, which can be impacted by difficulty of the learning activity. When students do not understand the basic context of the activity, they will be unable to engage in content to the full extent. Students are more likely to understand and apply information if the activity is tailored to the students' learning needs (Hattie and Timperley, 2007). When compared to other subjects, science is failing to pique interest in and engage students as they age, ultimately causing decreased awareness of science-related matters through adulthood (Osborne and Collins, 2001; Pell and Jarvis, 2001).

Another factor to consider that can be impacted by enjoyment is student (f) Motivation toward Science. Motivation can drop during early adolescence making this a critical intervention period for attitudinal assessment. Motivation drives choices which ultimately can influence preference for a given subject area. If students do not engage in the learning activity, preference can be skewed potentially leading to disinterest in science throughout the lifespan (Bathgate et al., 2013).

Social aspects of science should also be considered when assessing attitudes. For example, (g) Attitudes of Friends and Peers toward Science is an area of interest in many areas of research because of its impact on student behavior. Researchers have found a strong positive correlation between friends' ATS indicating that peers influence individual attitudes (Breakwell and Beardsell, 1992; Chibeci, 1986; George, 2000). Some research has indicated that peers have a greater influence on attitudes than parents and teachers (George, 2000).

While peers can be highly influential, (h) Attitudes of Family toward Science, specifically parents, has been strongly correlated with the respective child's attitudes (Breakwell and Beardsell, 1992; Yilmaz-Tuzun, 2008). The home environment and family/parental ambitions for the student's educational future can also influence attitudes. If family/ parents do not engage or create reasonable performance expectations, students are less likely to create positive ATS. Families/parents should support student learning through engagement and encouragement (Yilmaz-Tuzun, 2008).

Scientific Attitude Tools. A review of the last 12 years of science education attitudes literature (Povtin and Hasni, 2014) indicates that while the data demonstrates that effort produces gains in attitudes, the scientific community lacks understanding about which exact program features produce the greatest science attitude gains. Potvin and Hasni recommend next steps in science education research should focus more thoroughly on details of program features that produce greatest gain in attitude impact (Povtin and Hasni, 2014). This recommendation bolsters the justification for improved tools for measuring ATS. However, some researchers will state that the existing tools are adequate, while others express a need for tool development evolution to stay current with changing cultures as well as addressing issues of diversity.

Developing valid and reliable ATS instruments has been 
ongoing since Victor Knoll challenged researchers to measure attitudes more scientifically (Knoll, 1935; Zhang and Campbell, 2010). Numerous instruments measuring science attitudes have been adopted and widely used for many years (Blalock et al., 2008; Gokhale et al., 2009; Zhang and Campbell, 2010). Many resources have been featured as a gold standard, and rightfully so, for the contributions made to science education with those tools. At the same time, criticism of the current instruments includes length, limited use of psychometrics, and assessment of too many constructs (Barmby et al., 2008; Gokhale et al., 2009; Krynowsky, 1988; Munby, 1983; Osborne et al., 2003; Pearl, 1974; Zhang and Campbell, 2010). Given the issues with current ATS instruments, our research team decided to work towards creating a more efficient short-form using a quantitative Likert-scale approach that is statistically sound, internally consistent, with distinct unidimensional subscales (Gardner, 1995; Schibeci, 1984).

\section{METHODOLOGY}

Study Design. The FoodMASTER Initiative is a compilation of activities aimed at using food as a tool to teach mathematics and science. The curriculum used for this study, FoodMASTER Intermediate (FMI), is a ten-chapter curriculum consisting of 24 hands-on food-based science lessons geared towards students in grades three to five. As part of this curricular initiative, a 50-item, ATS assessment instrument was implemented in 34 fourth-grade classrooms in Ohio (OH) and North Carolina (NC) during the 2008-2010 academic years. Responses to this 50 -item instrument were used to guide the creation of a shortened version. In order to reduce the instrument from 50-items to a length more appropriate for students in elementary school levels, the statistical properties were analyzed to identify items that were not reliable, not valid, or redundant. Both descriptive statistics and exploratory factor analysis were used to guide decisions as to which items could be eliminated. University Institutional Review Board approved all study protocol and instruments prior to implementation.

Instrument. Based on researcher-identified ATS in the professional literature (Blalock et al., 2008; Breakwell and Beardsell, 1992; Chibeci, 1986; Christidou, 2011; Elliot and Sheldon, 1997; Fouad and Smith, 1996; George, 2000; Germann, 1988; Gokhale et al., 2009; Kind et al., 2007; Matterm and Schau, 2002; Osborne et al., 2003; Pell and Jarvis, 2001; Povtin and Hasni, 2014; Tosun, 2000; Yilmaz-Tuzun, 2008; Zhang and Campbell, 2010), an eight construct, 50item measurement tool was created to include:

1. Perception of the Science Teacher - five items,

2. Self-esteem at Science - four items,

3. Fear of Failure on Course - six items,

4. Value of Science - nine items,
5. Enjoyment of Science - ten items,

6. Motivation toward Science - five items,

7. Attitudes of Friends and Peers toward Science - six items, and;

8. Attitudes of Family toward Science - five items.

The Flesch-Kincaid Reading Level of the instrument was 1.9 , suggesting the instrument is appropriate for children at or above proficiency level at the beginning of fourth-grade. The researchers employed a modified Likert survey (Figure 1). The ordinal scale included responses one through five (i.e. 1 - "Really Do Not Agree", 2 - "Do Not Agree", 3 "Kind of Agree", 4 - "Agree", and 5 - "Super Agree". While the terms used to anchor the responses 1 through 5 might seem "goofy" to traditionalists, this scale was developed for administration to younger students and the language was an attempt to create an ordinal scale that "made sense" for younger respondents.

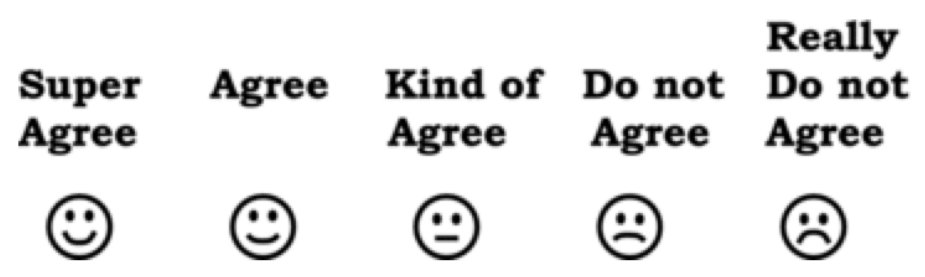

Figure 1. Modified Likert scale.

Sample. Researchers desired to optimize as many completed surveys as possible for the factor analysis. For this reason, it is important to distinguish the sample of students participating in the study with the number of completed surveys analyzed as part of the factor analysis. The initial sample of students participating in this study was comprised of $(n=758)$ children in 34 fourth-grade classrooms in select counties of $\mathrm{NC}$ and $\mathrm{OH}$ participating in a food-based science education curriculum intervention (FoodMASTER Intermediate). Ideally, the study's methodology was designed to administer to each child both pre and post versions of the survey, yielding a target for completed surveys of double that number $(n=1,516)$. However, not all students completed both versions of the survey. Moreover, only surveys, whether pre- or post- versions, for which science attitudes questions were completed to their entirety were included in the analysis, thus yielding a smaller and odd number of completed surveys $(n=1,117)$.

Having established 1,117 as the number of completed surveys utilized for the factor analysis, and bearing in mind that many students completed the survey twice for pre-and post measurements, the following demographics reflect the makeup of completed surveys rather than that of the initial student body in the study. Gender was distributed fairly equally among completed surveys. Females represented a slight majority $(\mathrm{n}=567 ; 50.8 \%)$ of the completed surveys, 
and males represented a similar, albeit smaller proportion $(\mathrm{n}=514 ; 46.0 \%)$. Gender was not specified for a small number $(n=36 ; 3.2 \%)$ of the completed surveys. Most completed surveys represented White students $(n=811 ; 72.6 \%)$, with less than one fifth representing Black/African-American students $(\mathrm{n}=175 ; 15.7 \%)$, and roughly one in twenty $(\mathrm{n}=50$; $4.5 \%$ ) representing Hispanic or Latino students. The majority of surveys were completed by students ages nine $(n=134$; $12.0 \%), 10(\mathrm{n}=793 ; 71.0 \%)$ or $11(\mathrm{n}=129 ; 11.5 \%)$. Fewer than one in ten surveys were completed by students $(n=79$; $7.1 \%$ ) with a documented individual education plan (IEP). Completed surveys were were distributed fairly equally in terms of state of respondent's residence. A slight majority were completed by students in Ohio $(\mathrm{n}=640 ; 57.3 \%)$, while the remainder $(\mathrm{n}=477 ; 42.7 \%)$ were completed by students in North Carolina. Over half of the completed surveys reflect students who received the FoodMASTER intervention $(n=671 ; 60.1 \%)$, and roughly 4 out of 10 surveys $(n=446$; $39.9 \%$ ) were completed by students assigned to the control group. One advantage to including students' responses to both pre- and post- administrations of the instrument is that analysis of item responses considers both contexts, thus helping create a shortened version that is appropriate for administration at any point during the curriculum. Discrepancies between sample size (n) and the number of responses to a given item are due to participants opting not to respond.

Statistical Tests Employed. Three general approaches were used to analyze the 50-items and select those that comprise the shortened version instrument. First, descriptive statistics were used to examine patterns of respondent fatigue, as manifested by items not being completed. Second, the means and standard deviations for individual item responses were analyzed to identify those that best detected variations in attitudes. Third, exploratory factor analysis was used to explore the construct validity of each of the eight subscales. The following is a brief description of each test.

Descriptive Statistics. Descriptive statistics, which included frequency counts, response means, and standard deviations, were used to explore characteristics of instrument items such as distribution and frequency (Green and Salkind, 2005). Descriptive statistics were not used to compare treatment and comparison groups. The primary role of the application of descriptive statistics in this study was to see if the instrument item discriminated among participant responses.

Cronbach's Alpha. The Cronbach's alpha was used as a measure to assess the integrity (i.e. "internal consistency") and "can be used with instruments made up of items that can be scored with three or more possible values" (Huck, 2008, p. 81). This test was used to examine the reliabilities of items in the instrument.

Factor Analysis. We employed factor analysis, specifical- ly principal components analysis (PCA), with appropriate rotation (i.e. varimax/oblimin) in order to reduce the number of items in the survey. Factor analysis is generally "viewed as a data-reduction technique" that can within a study take "different sets of measures that reflect different dimensions of a broader conceptual system" and "yield factors that represent these dimensions" (Green and Salkind, 2005, p. 312).

Combined, these statistical tests comprise a robust attempt at establishing psychometrics for the (AASC-4) instrument.

\section{RESULTS}

Respondent Fatigue. Respondent fatigue was one factor used to inform reduction of items. Visual examination of those items left blank illustrates how participant fatigue climbed significantly after 38-items. Figure 2 demonstrates the number of participants that left each item blank. For items one through eight, the average number of participants leaving any of those items incomplete was 6.97 (s.d. $=2.83$ ). The average for items $39-50$ was 17.75 (s.d.=3.22), which is more than double the mean of the first 38 items.

In this first step of item analysis, the purpose was not to identify which particular items may cause fatigue, but instead to inform how many items overall are likely to cause fatigue. Ideally, researchers and educators are best informed about students' attitudes when respondents complete every item on the instrument. Respondent fatigue thus potentially compromises the validity of items, especially those appearing near the end of the instrument. While non-response from 18 of 1,313 participants $(1.37 \%)$ for a particular item may initially seem trivial, consider that these accumulate over the 50 items, thus reducing the number of fully completed surveys that can be used for analysis (i.e. all items for a subscale need to be answered to get a score)

Response Means and Standard Deviations. A fundamental purpose of administering a science attitudinal instrument to K-12 students is to highlight differences in attitudes among the participants. Means and standard deviations, therefore, are very informative. Figure 3 illustrates the means and standard deviations for each of the 50-items. Means are illustrated as gray bars, and black dots reflect the respective standard deviations. Items with extremely high mean levels of agreement or disagreement, when coupled with low standard deviations, fail to differentiate attitudes among students. Therefore, they are less informative than items with both central means $(\sim 3.0)$ and high standard deviations. For example the item "I want to get a good grade in science class" has the highest mean response and the lowest standard deviation, suggesting most students agreed with this item. Therefore, a teacher wishing to differentiate instruction or an educator wishing to distinguish attitudes among gender, 

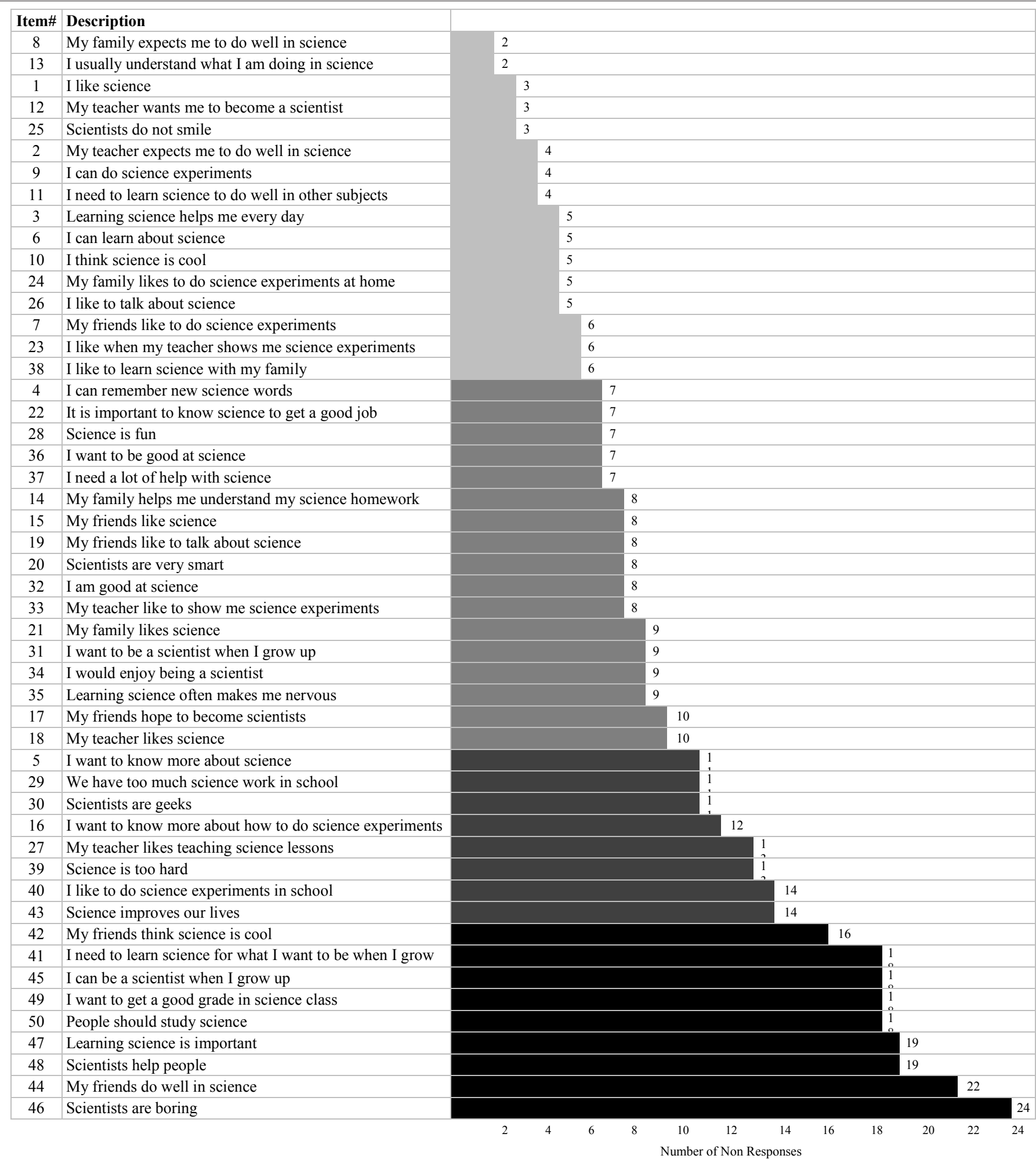

Figure 2. Frequency with which items were left blank on 50-item instrument.

treatment level, or other important categorical variables of interest is likely to find little utility for this item. On the other hand, items with a central mean and large standard deviation suggest that most responses were divided at opposite ends of the ordinal scale. For example, the item "I can be a scientist when I grow up" had a mean score of 3.20 (s.d.=1.55). For this item, over $50 \%$ of participants selected either end of the ordinal scale (Really Do Not Agree, or Super Agree), thus highlighting differences among students belonging to various categorical levels. Ultimately, these types of items with large standard deviations may be much more informative for educators and researchers.

Exploratory Factor Analysis. In addition to participant fatigue and descriptive statistics for item responses, exploratory factor analysis helps inform the extent to which a particu- 


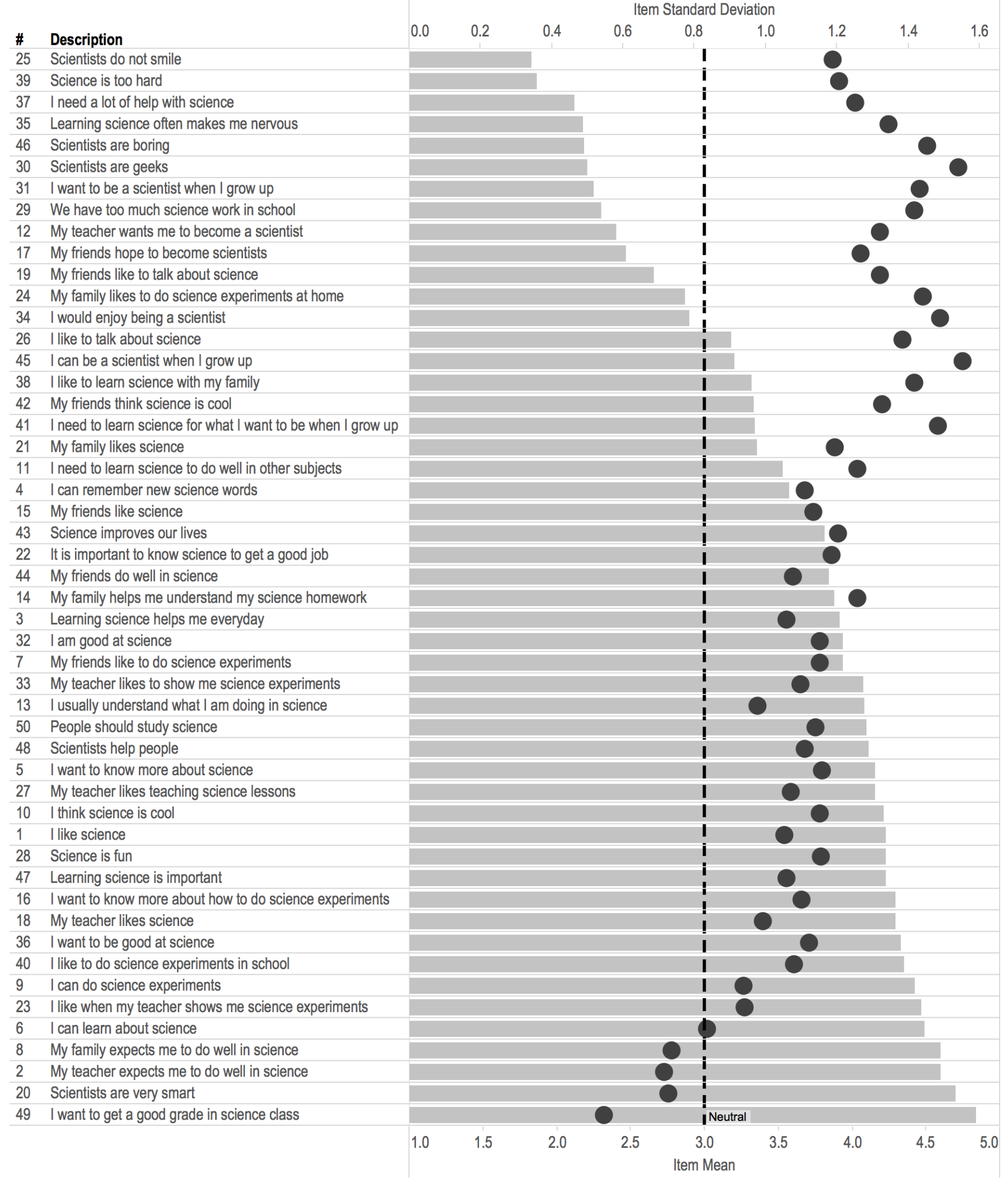

\footnotetext{
Measure Names

Item Mean

Item Standard Deviation
}

Figure 3. Means and standard deviations for individual items on the 50-item instrument. 
Table 1. Exploratory Factor Analysis Eigenvalues

\begin{tabular}{cccc}
\hline & & \multicolumn{2}{c}{ Initial Eigenvalues } \\
\cline { 3 - 4 } Component & Total & \% Variance & Cumulative \% \\
\hline 1 & 15.01 & 30.03 & 30.03 \\
2 & 3 & 6.01 & 36.04 \\
3 & 2.22 & 4.44 & 40.48 \\
4 & 2 & 4 & 44.47 \\
5 & 1.72 & 3.43 & 47.9 \\
6 & 1.38 & 2.76 & 50.66 \\
7 & 1.26 & 2.52 & 53.18 \\
8 & 1.2 & 2.41 & 55.59 \\
9 & 1.19 & 2.37 & 57.96 \\
10 & 1.06 & 2.12 & 60.08 \\
\hline
\end{tabular}

lar item fits well with its intended subscale. The sample size here fulfills Kass and Tinsley's (1979) recommendation for five to ten participants per item for factor analysis as well as Nunnally's more stringent standards requiring at least ten participants per item (Nunnally, 1998). Some authors suggest absolute minimally adequate sample sizes for factor analysis. Comrey and Lee rate sample sizes of $(n=200)$ as fair and $(n=300)$ as good (Comrey and Lee, 1992), while Tabachnik and Fidell rate absolute sample sizes of $(n=300)$ as adequate (Tabachnik and Fidell, 2007).

Exploratory Principal Components Analysis (PCA) using varimax rotation yielded ten distinct subscales with eigenvalues $>1.0$ when initially reducing the 50 -item instrument. These ten subscales accounted for $60.08 \%$ of the total variance, suggesting some overlap among the instrument's intended eight subscales. Table 1 illustrates for each of these ten factors the eigenvalue, the percent of variance explained for by that particular factor, and the cumulative percentage of variance explained.

Table 2, The Rotated Component Matrix, illustrates factor loadings for each of the 50 instrument items, the factor upon which that item loaded most heavily, and for purposes of contrast the subscale for which that item was intended. A summary of these results is organized below in relation to the eight proposed subscales of the instrument. For this discussion, "subscale" refers to those components intended by instrument authors, while "factor" refers to the grouping of items resulting from the principal components analysis.

1. Perception of the Science Teacher - Three of the five Perception of the Science Teacher items comprise a distinct factor that contains no remaining items. Item number 12 , "My teacher wants me to become a scientist," was found to be associated with the Enjoyment of Science item 26, "I like to talk about science," and two Value of Science items: item number 31, "I want to be a scientist when I grow up," and item number 34, "I would enjoy being a scientist." It was also associated with a single Self-esteem at Science item.

2. Self-esteem at Science - Four Self-esteem at Science items were drafted for the original instrument, yet scattered among three separate factors. All four items factored out as being associated with other constructs. Item 6 , "I can learn about science", and item 9, "I can do science experiments," factored out as being associated with items from the Motivation toward Science and Enjoyment of Science subscales. Item 45," I can be a scientist when I grow up," came out as belonging to a factor containing items for Value of Science, Enjoyment of Science, and Perception of the Science Teacher. Item 4, "I can remember new science words", factored out as belonging to the Fear of Failure on Course items.

3. Fear of Failure on Course - Five of the six items in the Fear of Failure on Course construct formed a factor that also contained a single item from the Self-esteem at Science construct, "I can remember new science words." The sixth Fear of Failure on Course construct item, "Science is too hard," was associated with two items from the Value of Science construct, one Self-esteem at Science construct item, and one Perception of the Science Teacher construct item.

4. Value of Science - Nine of the 50 items comprised the Value of Science construct. These nine items were associated with four distinct factors. Three of these items, (a) 22 - "It is important to know science to get a good job;" (b) 41 - "I need to learn science for what I want to be when I grow up," and; (c) 48 - "Scientists help people," were associated with four items from the Science as a Preference construct. Two of the items, (a) 31 - "I want to be a scientist when I grow up," and; (b) 34 - "I would enjoy being a scientist," were associated with an item from the Self-esteem at Science construct, another from the Perception of the Science Teacher construct, and yet another from the Enjoyment of Science construct.

5. Enjoyment of Science - Ten of the 50 items comprised the Enjoyment of Science construct. Five of these items were associated with two items from the Science Confidence construct: "I can learn about science," and "I can do science experiments." These five items were also associated with two items from the Self-esteem at Science construct: "I want to know more about science," and "I want to know more about how to do science experiments." Four of the items were found to be a factor associated with three items from the Value of Science construct. The remaining item from this construct, "I like to talk about science," belonged to a factor containing two Value of Science construct items, one item from the Self-esteem at Science construct, and another item from the Perception of the Science Teacher construct.

6. Motivation toward Science - The five Motivation toward Science construct items were found in three distinct factors. Item 5, "I want to know more about science," and item 16, "I want to know more about how to do science experiments," were associated with a factor containing a mix 
Table 2. Rotated Component Matrix for Exploratory Factor Analysis

\begin{tabular}{|c|c|c|c|c|c|c|c|c|c|c|c|c|c|}
\hline & & \multicolumn{11}{|c|}{ Component } & \\
\hline & & 1 & 2 & 3 & 4 & 5 & 6 & 7 & 8 & 9 & 10 & & \\
\hline 1 & I like science & .686 & .178 & .250 & .127 & .265 & .079 & -.098 & -.038 & .035 & .039 & 1 & Science as a preference \\
\hline 2 & My teacher expects me to do well in science & .130 & .107 & .014 & .042 & .084 & .197 & -.129 & -.003 & -.750 & -.013 & 9 & Teacher \\
\hline 3 & Learning science helps me every day & .412 & .511 & .146 & .126 & .115 & .105 & -.073 & .058 & .238 & -.097 & 2 & Science as a preference \\
\hline 4 & I can remember new science words & .217 & .328 & .100 & .098 & .399 & .049 & .026 & .259 & .251 & -.154 & 5 & Science Confidence \\
\hline 5 & I want to know more about science & .681 & .273 & .283 & .110 & .140 & .112 & -.130 & .020 & .116 & -.032 & 1 & Science Motivation \\
\hline 6 & I can learn about science & .502 & .293 & .091 & .028 & .273 & .139 & -.095 & .040 & .254 & .026 & 1 & Science Confidence \\
\hline 7 & My friends like to do science experiments & .414 & .072 & -.112 & .605 & .025 & .075 & .027 & .200 & .055 & -.118 & 4 & Science Peer Influence \\
\hline 8 & My family expects me to do well in science & .160 & .093 & -.011 & .146 & .046 & .021 & .025 & .134 & .708 & .234 & 9 & Science family \\
\hline 9 & I can do science experiments & .521 & .116 & -.035 & .178 & .255 & .096 & .063 & .274 & .045 & .054 & 1 & Science Confidence \\
\hline 10 & I think science is cool & .744 & .208 & .237 & .218 & .119 & .078 & -.164 & .028 & .034 & -.002 & 1 & Science as a preference \\
\hline 11 & I need to learn science to do well in other & .119 & .559 & .158 & .072 & -.017 & .084 & .112 & -.014 & .298 & -.139 & 2 & Science Motivation \\
\hline 12 & My teacher wants me to become a scientist & .069 & .258 & .480 & .249 & -.011 & .233 & .155 & .026 & .124 & -.195 & 3 & Teacher \\
\hline 13 & I usually understand what I am doing in science & .313 & .257 & .199 & .160 & .555 & .114 & .031 & .080 & .204 & .142 & 5 & Ease of science learning \\
\hline 14 & My family helps me understand my science & .099 & .108 & .065 & .164 & .034 & -.051 & .018 & .501 & .283 & .232 & 8 & nce family \\
\hline 15 & My friends like science & .367 & .107 & .079 & .698 & .138 & .104 & -.034 & .109 & .106 & .013 & 4 & Science Peer Influence \\
\hline 16 & I want to know more about how to do science & .712 & .201 & .112 & .124 & -.008 & .025 & -.083 & .158 & .086 & .167 & 1 & Science Motivation \\
\hline 17 & My friends hope to become scientists. & .031 & .141 & .479 & .534 & -.120 & .130 & .073 & .096 & .129 & -.097 & 4 & Science Peer Influence \\
\hline 18 & My teacher likes science & .109 & .133 & .067 & .110 & .118 & .759 & .004 & .036 & .117 & .066 & 6 & Teacher \\
\hline 19 & My friends like to talk about science & .151 & .162 & .380 & .570 & -.030 & .098 & .034 & .207 & .042 & -.018 & 4 & Science Peer Influence \\
\hline 20 & Scientists are very smart & .137 & .253 & .058 & .035 & .001 & .270 & -.047 & -.059 & .123 & .532 & 1 & Science career/scientists \\
\hline 21 & My family likes science & .152 & .217 & .244 & .258 & .112 & .187 & -.048 & .605 & .034 & .029 & 8 & Science family \\
\hline 22 & It is important to know science to get a goo & .140 & .678 & .164 & .141 & .032 & .040 & .069 & .162 & .106 & .032 & 2 & Science career/scientists \\
\hline 23 & I like when my teacher shows me science & .654 & .045 & .053 & .119 & .014 & .148 & -.104 & .212 & .192 & .139 & 1 & Science as a preference \\
\hline 24 & My family likes to do science experiments at & .219 & .140 & .206 & .125 & -.039 & .158 & -.028 & .674 & -.002 & -.142 & 8 & Science family \\
\hline 25 & Scientists do not smile & -.036 & -.089 & .104 & .047 & -.062 & -.118 & .671 & -.172 & -.098 & .129 & 7 & Science career/scientists \\
\hline 26 & I like to talk about science & .373 & .230 & .497 & .281 & .084 & .092 & -.133 & .237 & .023 & .098 & 3 & Science as a preference \\
\hline 27 & My teacher like teaching science lessons & .143 & .136 & .118 & .156 & .102 & .794 & -.048 & .112 & .095 & .086 & 6 & Teacher \\
\hline 28 & Science is fun & .704 & .208 & .267 & .185 & .135 & .106 & -.128 & .058 & .025 & .188 & 1 & Science as a \\
\hline 29 & We have too much science work in school & -.166 & -.091 & -.108 & -.009 & -.319 & -.023 & .577 & .120 & -.020 & -.011 & 7 & Ease of science learning \\
\hline 30 & Scientists are geeks & -.226 & -.096 & -.248 & -.108 & -.101 & .054 & .660 & -.032 & -.025 & -.191 & 7 & Science career/scientists \\
\hline 31 & I want to be a scientist when I grow up & .185 & .150 & .798 & .017 & -.030 & .037 & -.098 & .119 & -.014 & .013 & 3 & Science career/scientists \\
\hline 32 & I am good at science & .283 & .245 & .263 & .128 & .541 & .188 & .027 & .122 & .002 & .344 & 5 & Ease of science learning \\
\hline 33 & My teacher likes to show me science & .274 & .106 & .096 & .173 & .080 & .695 & -.071 & .175 & .045 & .106 & 6 & Teacher \\
\hline 34 & I would enjoy being a scientist & .253 & .147 & .725 & .137 & .087 & .090 & -.188 & .161 & .012 & .140 & 3 & Science career/scientists \\
\hline 35 & Learning science often makes me nervous & .001 & .068 & .137 & .012 & -.570 & -.069 & .287 & .069 & -.035 & .054 & 5 & Ease of science learning \\
\hline 36 & I want to be good at science & .367 & .317 & .163 & .090 & .163 & .020 & -.066 & .122 & .161 & .501 & 1 & Science Motivation \\
\hline 37 & I need a lot of help with science & -.093 & .031 & .063 & .006 & -.805 & -.036 & .067 & -.066 & -.009 & -.012 & 5 & Ease of science learning \\
\hline 38 & I like to learn science with my family & .242 & .304 & .304 & .084 & .019 & .127 & -.177 & .577 & -.025 & .078 & 8 & Science family \\
\hline 39 & Science is too hard & -.221 & -.002 & -.136 & -.071 & -.701 & -.076 & .306 & .031 & -.010 & -.085 & 5 & Ease of science learning \\
\hline 40 & I like to do science experiments in school & .636 & .135 & .033 & .160 & .045 & .175 & -.141 & .216 & .051 & .203 & 1 & Science as a preference \\
\hline 41 & I need to learn science for what I want to be when I & .150 & .545 & .349 & .081 & -.075 & -.025 & -.087 & .136 & .009 & .109 & 2 & Science career/scientists \\
\hline 42 & My friends think science is cool & .226 & .170 & .228 & .717 & .040 & .126 & -.167 & .080 & -.032 & .198 & 4 & Science Peer Influence \\
\hline 43 & Science improves our lives & .181 & .641 & .104 & .176 & .092 & .115 & -.096 & .142 & -.018 & .075 & 2 & Science as a preference \\
\hline 44 & My friends do well in science & .072 & .252 & .030 & .562 & .160 & .178 & -.104 & .067 & .124 & .188 & 4 & Science Peer Influence \\
\hline 45 & I can be a scientist when I grow up & .156 & .196 & .583 & .067 & .125 & .048 & -.168 & .187 & -.006 & .209 & 3 & Science Confidence \\
\hline 46 & Scientists are boring & -.193 & -.060 & -.307 & -.140 & -.190 & .018 & .595 & -.045 & .026 & -.227 & 7 & Science career/scientists \\
\hline 47 & Learning science is important & .234 & .650 & .021 & .115 & .093 & .084 & -.189 & .115 & .081 & .301 & 2 & Science as a preference \\
\hline 48 & Scientists help people & .122 & .611 & .085 & .069 & -.001 & .180 & -.167 & .097 & -.118 & .307 & 2 & Science career/scientists \\
\hline 49 & I want to get a good grade in science class & .295 & .166 & .063 & .018 & .076 & .096 & -.082 & .061 & .402 & .455 & 1 & Science Motivation \\
\hline 50 & People should study science & .254 & .592 & .123 & .127 & .029 & .122 & -.155 & .102 & .081 & .249 & 2 & Science as a preference \\
\hline
\end{tabular}

of Self-esteem at Science and Enjoyment of Science items. Item 11, "I need to learn science to do well in other subjects," factored out as being associated with items from the Enjoyment of Science and Value of Science subscales. Item 36 , "I want to be good at science," and item 49, "I want to get a good grade in science class," factored out as being associated with an item from the Value of Science construct.
7. Attitudes of Friends and Peers toward Science - The six Attitudes of Friends and Peers toward Science construct items comprised an intact factor that showed no overlap with other factors.

8. Attitudes of Family (Parents) toward Science - Four of the five Attitudes of Family (Parents) toward Science items form an intact factor. Item 8 , "My family expects me to do 
Table 3. Final 24-item Short-Form Instrument Items and Subscales

\begin{tabular}{|c|c|c|}
\hline \# & Item & Intended Subscale \\
\hline 18 & My teacher likes science & Perception of the Science Teacher/Expectations \\
\hline 27 & My teacher likes teaching science lessons & Perception of the Science Teacher/Expectations \\
\hline 33 & My teacher likes to show me science experiments & Perception of the Science Teacher/Expectations \\
\hline 6 & I can learn about science & Self-esteem at Science \\
\hline 9 & I can do science experiments & Self-esteem at Science \\
\hline 45 & I can be a scientist when I grow up & Self-esteem at Science \\
\hline 35 & Learning science often makes me nervous & Fear of Failure on Course \\
\hline 37 & I need a lot of help with science & Fear of Failure on Course \\
\hline 39 & Science is too hard & Fear of Failure on Course \\
\hline 22 & It is important to know science to get a good job & Value of Science \\
\hline 41 & $\begin{array}{l}\text { I need to learn science for what I want to be when I grow } \\
\text { up }\end{array}$ & Value of Science \\
\hline 48 & Scientists help people & Value of Science \\
\hline 10 & I think science is cool & Enjoyment of Science \\
\hline 28 & Science is fun & Enjoyment of Science \\
\hline 40 & I like to do science experiments in school & Enjoyment of Science \\
\hline 5 & I want to know more about science & Motivation toward Science \\
\hline 11 & I need to learn science to do well in other subjects & Motivation toward Science \\
\hline 36 & I want to be good at science & Motivation toward Science \\
\hline 16 & My friends like science & Attitudes of Friends and Peers toward Science \\
\hline 19 & My friends like to talk about science & Attitudes of Friends and Peers toward Science \\
\hline 42 & My friends think science is cool & Attitudes of Friends and Peers toward Science \\
\hline 21 & My family likes science & Attitudes of Parents (Family) toward Science \\
\hline 24 & My family likes to do science experiments at home & Attitudes of Parents (Family) toward Science \\
\hline 38 & I like to learn science with my family & Attitudes of Parents (Family) toward Science \\
\hline
\end{tabular}

well in science," factored out as being associated with a single Perception of the Science Teacher item. Clearly, the 50item instrument, in addition to causing respondent fatigue, results in considerable conceptual overlap among the eight intended subscales.

The decision to include eight constructs was based on the review of the literature (i.e. what was traditionally and regularly included in other instruments) and a subjective decision to maintain as 'robust' an instrument as possible while reducing the overall number of items. We also made the subjective determination that two items per construct, was not substantial enough of a measurement. Three items added a lot to the substantive measure of each construct. We also wanted the short form to have the same number of items for each construct because we wanted them to be 'balanced' rather than giving more weight to one than another.

Short-Form Instrument Analyses. The initial goal was to reduce considerably the 50 -item instrument to develop a reliable and valid shortened form. In order to assign a given
Table 4. Reliabilities for 50-Item and Short-Form Instruments

\begin{tabular}{|c|c|c|}
\hline Subscale & 50-Item Survey & $\begin{array}{c}\text { Short Form } \\
\text { 24-Item Survey } \\
\end{array}$ \\
\hline $\begin{array}{l}\text { Perception of the Science } \\
\text { Teacher }\end{array}$ & 0.7 & 0.791 \\
\hline Self-esteem at Science & 0.605 & 0.522 \\
\hline Fear of Failure on Course & 0.2 & 0.694 \\
\hline Value of Science & 0.478 & 0.779 \\
\hline Enjoyment of Science & 0.89 & 0.831 \\
\hline Motivation toward Science & 0.711 & 0.583 \\
\hline $\begin{array}{l}\text { Attitudes of Friends and } \\
\text { Peers toward Science }\end{array}$ & 0.818 & 0.769 \\
\hline $\begin{array}{l}\text { Attitudes of Parents } \\
\text { (Family) toward Science }\end{array}$ & 0.706 & 0.754 \\
\hline
\end{tabular}

number of items consistently to each intended subscale, researchers had to choose a final shortened version that had a total number of items that is a multiple of eight. The researchers for this study decided to choose three items for each of the eight subscales to produce a shortened instru- 
ment containing 24 items. Based on a combination of results from the exploratory PCA and descriptive statistics for each of the 50 items, the final 24 items of the short-form instrument are listed in Table 3. This short-form version of the instrument has a Flesch-Kincaid Grade Level of 1.4, which is even lower than that for the 50-item instrument (1.9).

Up to this point in the study, analyses have served to reduce the 50-item instrument to the 24-item short form version. The discussion now shifts to analyzing the integrity of the 24-items chosen for the short-form version. Table 4 illustrates the Cronbach Alpha reliabilities for each of the eight subscales in both the original 50-item version and the 24-item short-form version. Utilization of the short-form instrument increased reliability for Fear of Failure on Course from 0.200 to 0.694 , Value of Science from 0.478 to 0.779 , Attitudes of Family (Parents) toward Science from 0.706 to 0.754, and Perception of the Science Teacher from 0.700 to 0.791. In contrast, utilization of the short-form version of the instrument resulted in decreased reliabilities for: Enjoyment of Science from 0.890 to 0.831 , Self-esteem at Science from 0.605 to 0.522 , Motivation toward Science from 0.711 to 0.583 , and Attitudes of Friends and Peers toward Science from 0.818 to 0.769 . Although some decreases in reliability resulted from shortening the instrument, Table 4 demonstrates that the short-form version of the instrument provides better overall reliability among the eight subscales.

Despite shortening the instrument, challenges continue to exist for certain constructs, namely Self-esteem at Science, Motivation toward Science, Value of Science. To further examine the psychometric properties (correlation) of the shortform instrument, confirmatory PCA using direct oblimin rotation (delta $=0$ ) was conducted on only those responses to the 24 short-form items, with the specification that items fit within the eight factors. Please note that this is separate and distinct from the factor analysis used to inform which item to select for the short form version.

For this confirmatory factors analysis, the 24 items were tested as if they had been stand-alone when administered to students. However, student responses to these 24 items were impacted, directly or indirectly, by responses to the remaining 26 of 50 items in the original instrument. Regardless of this limitation, a retrospective factor analysis of the subset of 24 items chosen helps to inform how well the short-form version is likely to perform.

Table 5, the Rotated Structure Matrix, illustrates factor loadings for each of the 24 items, the respective factor upon which that item loaded most heavily, and for purposes of contrast, the construct for which that item was intended. For the 24-item short form instrument, items for the following constructs formed intact factors:

1. Attitudes of Friends and Peers toward Science,

2. Attitudes of Family (Parents) toward Science,

3. Perception of the Science Teacher, and

\section{Fear of Failure on Course.}

The remaining four constructs were not intact. While the three items chosen for the Science as a Preference construct factored out together, they were also associated with a single item intended for the Motivation toward Science construct. One of the three items intended for the Value of Science construct was associated with a Motivation toward Science item. And as is apparent from the results, Self-esteem at Science and Motivation toward Science items did not perform well in the factor analysis. It is important to note, however, that although some decreases in reliability resulted from shortening the instrument, Table 4 demonstrates that the short-form version of the instrument provides better overall reliability among the eight subscales.

\section{DISCUSSION AND CONCLUSION}

The development of a validated attitudinal assessment instrument is needed to help ensure scientific fields continue to attract young minds to further advance those disciplines. The proposed instrument helps to address the issues identified with current instruments. When considered in the context of fourth graders, affective instrument items related to future career intent may be too sophisticated a construct for which researchers can reasonably anticipate self-awareness (Nasir and Lin, 2013).

Response patterns for students completing the original 50 -item instrument suggested a shorter version would be more appropriate for widespread adoption in K-12 education. Educators wishing to measure science attitudes in a school setting need to control the environment for student attention spans when completing this type of instrument. For this reason, a shorter instrument may be more appropriate for widespread adoption in K-12 settings. Shorter instruments demand less time and other resources of students, teachers, and personnel responsible for data analysis. The shorter instrument also appears to be more optimally balanced with respect to the reliabilities for the eight subscales. More specifically, when particular subscale reliabilities decreased once the 50-item instrument was modified to the short-form instrument, there was a positive offset due to the respective gains for other subscales. Furthermore, research has suggested evaluating constructs individually, which could be completed by only assessing the validated constructs within the short-form instrument (Gardner, 1995; Schibeci, 1982; Schibeci, 1984).

The proposed ATS instrument could be used as a standard attitudinal assessment tool; however, many research opportunities still exist for optimizing the utility of the short-form science attitudes instrument. For example, some of the instrument's items ask students to share perceptions related to science careers. Given that this study involved fourth-grade students, it may be unrealistic to expect students from this 


\begin{tabular}{|c|c|c|c|c|c|c|c|c|c|c|c|}
\hline \multirow{2}{*}{ \# } & \multirow{2}{*}{ Item } & \multicolumn{8}{|c|}{ Component } & \multirow{2}{*}{$\mathbf{F}$} & \multirow{2}{*}{ Intended Subscale } \\
\hline & & 1 & 2 & 3 & 4 & 5 & 6 & 7 & 8 & & \\
\hline 6 & $\begin{array}{l}\text { I can learn about } \\
\text { science }\end{array}$ & 0.705 & -0.287 & 0.361 & 0.244 & -0.239 & -0.201 & -0.346 & 0.234 & 1 & Science Confidence \\
\hline 9 & $\begin{array}{l}\text { I can do science } \\
\text { experiments }\end{array}$ & .0 .424 & -0.24 & 0.282 & 0.157 & -0.313 & -0.292 & -0.197 & 0.831 & 8 & Science Confidence \\
\hline 45 & $\begin{array}{l}\text { I can be a scientist } \\
\text { when I grow up }\end{array}$ & 0.396 & -0.175 & 0.199 & 0.14 & -0.404 & -0.36 & -0.649 & -0.045 & 7 & Science Confidence \\
\hline 5 & $\begin{array}{l}\text { I want to know more } \\
\text { about science }\end{array}$ & 0.852 & -0.194 & 0.341 & 0.294 & -0.384 & -0.403 & -0.286 & 0.148 & 1 & Science Motivation \\
\hline 11 & $\begin{array}{l}\text { I need to learn } \\
\text { science to do well in } \\
\text { other subjects }\end{array}$ & 0.281 & 0.017 & 0.244 & 0.85 & -0.199 & -0.182 & -0.128 & 0.021 & 4 & Science Motivation \\
\hline 36 & $\begin{array}{l}\text { I want to be good at } \\
\text { science }\end{array}$ & 0.589 & -0.191 & 0.276 & 0.251 & -0.252 & -0.305 & -0.612 & 0.204 & 7 & Science Motivation \\
\hline 15 & $\begin{array}{l}\text { My friends like } \\
\text { science }\end{array}$ & 0.466 & -0.195 & 0.351 & 0.22 & -0.301 & -0.792 & -0.136 & 0.267 & 6 & Science Peer Influence \\
\hline 19 & $\begin{array}{l}\text { My friends like to } \\
\text { talk about science }\end{array}$ & 0.281 & 0.047 & 0.275 & 0.274 & -0.469 & -0.783 & -0.203 & 0.097 & 6 & Science Peer Influence \\
\hline 42 & $\begin{array}{l}\text { My friends think } \\
\text { science is cool }\end{array}$ & 0.418 & -0.09 & 0.346 & 0.151 & -0.343 & -0.853 & -0.375 & 0.127 & 6 & Science Peer Influence \\
\hline 21 & $\begin{array}{l}\text { My family likes } \\
\text { science }\end{array}$ & 0.326 & -0.131 & 0.365 & 0.215 & -0.777 & -0.476 & -0.306 & 0.083 & 5 & $\begin{array}{l}\text { Science Family Influence/Expec- } \\
\text { tations }\end{array}$ \\
\hline 24 & $\begin{array}{l}\text { My family likes to } \\
\text { do science experi- } \\
\text { ments at home }\end{array}$ & 0.262 & 0.002 & 0.251 & 0.24 & -0.851 & -0.298 & -0.116 & 0.242 & 5 & $\begin{array}{l}\text { Science Family Influence/Expec- } \\
\text { tations }\end{array}$ \\
\hline 38 & $\begin{array}{l}\text { I like to learn sci- } \\
\text { ence with my family }\end{array}$ & 0.435 & -0.05 & 0.294 & 0.222 & -0.788 & -0.343 & -0.463 & 0.085 & 5 & $\begin{array}{l}\text { Science Family Influence/Expec- } \\
\text { tations }\end{array}$ \\
\hline 18 & $\begin{array}{l}\text { My teacher likes } \\
\text { science }\end{array}$ & 0.233 & -0.161 & 0.821 & 0.21 & -0.206 & -0.239 & -0.12 & 0.066 & 3 & Teacher Influence/Expectations \\
\hline 27 & $\begin{array}{l}\text { My teacher likes } \\
\text { teaching science } \\
\text { lessons }\end{array}$ & 0.309 & -0.134 & 0.877 & 0.178 & -0.307 & -0.309 & -0.183 & 0.122 & 3 & Teacher Influence/Expectations \\
\hline 33 & $\begin{array}{l}\text { My teacher likes to } \\
\text { show me science } \\
\text { experiments }\end{array}$ & 0.385 & -0.145 & 0.801 & 0.131 & -0.321 & -0.313 & -0.288 & 0.261 & 3 & Teacher Influence/Expectations \\
\hline 10 & $\begin{array}{l}\text { I think science is } \\
\text { cool }\end{array}$ & 0.838 & -0.226 & 0.302 & 0.248 & -0.376 & -0.509 & -0.278 & 0.26 & 1 & Science as a Preference \\
\hline 28 & Science is fun & 0.837 & -0.221 & 0.343 & 0.249 & -0.385 & -0.477 & -0.357 & 0.264 & 1 & Science as a Preference \\
\hline 40 & $\begin{array}{l}\text { I like to do science } \\
\text { experiments in } \\
\text { school }\end{array}$ & 0.658 & -0.158 & 0.374 & 0.099 & -0.355 & -0.344 & -0.341 & 0.517 & 1 & Science as a Preference \\
\hline 35 & $\begin{array}{c}\text { Learning science } \\
\text { often makes me } \\
\text { nervous }\end{array}$ & -0.162 & 0.725 & -0.117 & 0.144 & -0.018 & -0.11 & 0.001 & 0.188 & 2 & Ease of Science Learning \\
\hline 37 & $\begin{array}{l}\text { I need a lot of help } \\
\text { with science }\end{array}$ & -0.136 & 0.829 & -0.137 & -0.018 & 0.025 & 0.066 & 0.019 & -0.299 & 2 & Ease of Science Learning \\
\hline 39 & Science is too hard & -0.379 & 0.8 & -0.224 & -0.056 & 0.119 & 0.231 & 0.17 & -0.157 & 2 & Ease of Science Learning \\
\hline 22 & $\begin{array}{l}\text { It is important to } \\
\text { know science to get } \\
\text { a good job }\end{array}$ & 0.276 & -0.041 & 0.232 & 0.762 & -0.355 & -0.321 & -0.429 & 0.228 & 4 & Science Career/Scientists \\
\hline 41 & $\begin{array}{l}\text { I need to learn sci- } \\
\text { ence for what I want } \\
\text { to be when I grow up }\end{array}$ & 0.316 & 0.041 & 0.136 & 0.42 & -0.351 & -0.322 & -0.615 & 0.078 & 7 & Science Career/Scientists \\
\hline 48 & $\begin{array}{l}\text { Scientists help } \\
\text { people }\end{array}$ & 0.29 & -0.036 & 0.319 & 0.271 & -0.259 & -0.215 & -0.783 & 0.205 & 7 & Science Career/Scientists \\
\hline
\end{tabular}


age group to have statistically reliable perceptions about future careers in science. Future research can replicate this study with participants of varying age ranges to determine if career-related aspirations differ with age. We fully intend for this instrument to continue to undergo revision as the instrument is applied across diverse populations because we view the activities of establishing validity and reliability as an on-going process (Houser, 2008).

Another potential area for research is to utilize this instrument to help assess the impact of science curricula on student ATS. Most often, educators focus on assessing cognitive development resulting from participation in science programs. These explorations of cognitive achievement can be enhanced greatly by exploring potential overlap with simultaneous affective development.

This instrument can also be administered longitudinally to explore how science attitudes form as students develop cognitively and affectively throughout subsequent grade levels. This type of research can be influenced further through integration with existing State Longitudinal Data Systems. When coupled on a large-scale basis with existing statewide data, longitudinal administration of science attitudes scales can help determine which factors may be associated with desirable and/or undesirable changes in student science attitudes.

\section{AUTHOR INFORMATION Corresponding Author}

Sebastian R. Diaz, Ph.D., J. D. Research Lead, Central Appalachian Consortium of Colleges of Osteopathic Medicine (CACCOM) Associate Professor, Family Medicine. Heritage College of Osteopathic Medicine. 349 Grosvenor Hall. 1 Ohio University. Athens OH 45701. 740-593-0464. diazs@ohio.edu.

\section{Author Contributions}

The manuscript was written through contributions of all authors. All authors have given approval to the final version of the manuscript.

\section{FUNDING SOURCES}

FoodMASTER is supported by a Science Education Partnership Award (SEPA) from the National Institutes of Health (NIH). The content is solely the responsibility of the authors and does not necessarily represent the official views of the NIH.

\section{ACKNOWLEDGMENTS}

The authors would like to thank the teachers and students for their participation.

\section{ABBREVIATIONS}

ATS: Attitudes Toward Science; AASC-4: Assessment of Attitudes in Science Constructs for Fourth Grade

\section{REFERENCES}

Barmby, P., Kind, P., and Jones, K. (2008). Examining changing attitudes in secondary school science. International Journal of Science Education, 30(8), 1075-1093.

Bathgate, M., Schunn, C., and Correnti, R. (2013). Children's motivation toward science across contexts, manner of interaction, and topic. Science Education, 98(2), 189-215.

Blalock, C., Lichtenstein, M., Owen, S., Pruski, L., Marshall, C., and Toepperwein, M. (2008). In pursuit of validity: A comprehensive review of science attitude instruments 1935 - 2005. International Journal of Science Education, 30, 961-977.

Breakwell, G. and Beardsell, S. (1992). Gender, parental and peer influences upon science attitudes and activities. Public Understanding Science, 1(2), 183-197.

Chibeci, R. (1986). Images of science and scientists and science education. Science Education, 70(2), 139-149.

Christidou, V. (2011). Interest, attitudes and images related to science: Combining students' voices with the voices of school science, teachers, and popular science. International Journal of Environmental Science Education, 6(2), 141-159.

Comrey, A. and Lee, H. (1992). A first course in factor analysis. 2nd ed. Hillsdale: Psychology Press.

Conroy, D., Metzler, J., and Hofer, S. (2003). Factorial invariance and latent mean stability of performance failure appraisals. Structural Equatin Modeling A Multidisciplinary Journal, 10, 401-422.

Elliot, A. and Sheldon, K. (1997). Avoidance achievement motivation: A personal goals analysis. Journal of Personality and Social Psychology, 73, 171-185.

Fouad, N. and Smith, P. (1996). A test of a social cognitive model for middle school students: Math and science. Journal of Council Psychology, 43, 338-346.

Gardner, P. (1995). Measuring attitudes to science: Unidimensionality and internal consistency revisited. Research Science Education, 25(3), 283-289.

George, R. (2000). Measuring change in students' attitudes toward science over time: An application of latent variable growth modeling. Journal of Science Education Technology, 9(3), 213-225.

Germann, P. (1998). Development of the attitude toward science in school assessment and its use to investigate the relationship between science achievement and attitude toward science in school. Journal of Research in Science Teaching, 25(8), 689-703.

Gokhale, A., Brauchle, P., and Machina, K. (2009). Development and validation of a scale to measure attitudes toward science and technology. International Journal of Information and Communication Technology Education, 38(5), 66-75. 
Green, S.B. and Salkind, N.J. (2005). Using SPSS for Windows and Macintosh: Analyzing and understanding data. Upper Saddle River, NJ: Pearson/Prentice Hall.

Hattie, J. and Timperley, H. (2007). The power of feedback. Review of Educational Research, 77(1), 81-112.

Houser, J. (2008). Precision, reliability, and validity: Essential elements of measurement in nursing research. Journal for Specialists in Pediatric Nursing, 13(4), 297-299.

Huck, S.W. (2008). Reading statistics and research. New York, Pearson.

Kass, R. and Tinsley, H. (1979). Factor analysis. Journal of Leisure Research, 11, 120-138.

Kind, P., Jones, K., and Barmby, P. (2007). Developing attitudes towards science measures. International Journal of Science Education, 29(7), 871-893.

Knoll, V. (1935). Measuring the scientific attitude. Journal of Abnormal Social Psychology, 30(2), 145-154.

Krynowsky, B. (1988). Problems in assessing student attitude in science education: A partial solution. Science Education, 72(4), 575-584.

Marsh, H.W. and Yeung, A.S. (1997). Coursework selection: Relations to academic self-concept and achievement. American Educational Research Journal, 34, 691-720.

Matterm, N. and Schau, C. (2002). Gender differences in science attitude-achievement relationships over time among white middle-school students. Journal of Research in Science Teaching, 39(4), 324-340.

Munby, H. (1983). Thirty studies involving the "scientific attitude inventory": What confidence can we have in this instrument? Journal of Research in Science Teaching, 20(2), 141-162.

Nasir, R. and Lin, L.S. (2013). The relationship between self-concept and career awareness amongst students. Asian Social Science, 9(1), 193-197.

Nunnally, J. Psychometric theory. (1998). 2nd Ed. New York: McGraw-Hill.

Osborne, J. and Collins, S. (2001). Pupils' views of the role and value of the science curriculum: A focus-group study. International Journal of Science Education, 23(5), 441-467.

Osborne, J., Simon, S., and Collins, S. (2003). Attitudes towards science: A review of the literature and its implications. International Journal of Science Education, 25(9), 10491079 .

Palmer, D. (2002). Factors contributing to attitude exchange amongst preservice elementary teachers. Science Education, 86(1), 122-138.

Pearl, R. (1974). The present status of science attitude measurement history, theory, and availability of measurement instruments. School of Science and Mathematics, 74(5), 375-381.

Pell, T. and Jarvis, T. (2001). Developing attitude to science scales for use with children of ages from five to eleven years. International Journal of Science Education, 23(8), 847-862.
Povtin, P. and Hasni, A. (2014). Interest, motivation, and attitude toward science and technology at K-12 levels: A systematic review of 12 years of educational research. Studies in Science Education, 50(1), 85-129.

Schibeci, R. (1982). Measuring student attitudes: semantic differential or Likert instruments? Science Education, 66(4), 565-570.

Schibeci, R. (1984). Attitudes to science: An update. Journal of Student Science Education, 11(1), 26-59.

Tabachnik, B. and Fidell, L. (2007). Using multivariate statistics. 6th Ed. Boston: Pearson.

Tosun, T. (2000). The beliefs of preservice elementary teachers toward science and science teaching. School Science and Mathematics, 100(7), 374-379.

Wahl, K.H. and Blackhurst, A. (2000). Factors affecting the occupational and educational aspirations of children and adolescents. Professional School Counseling, 3(5), 367-374.

Weinburgh, M.H. (2003). The effects of systemic reform on urban, African American fifth grade students' attitudes toward science. Journal of Women Minor Science Engineering, 9(1), 53-72.

Yager, R. and Penick, J. (1986). Perceptions of four age groups toward science classes, teachers, and the value of science. Science Education, 70(4), 355-363.

Yilmaz-Tuzun, O. (2008). Preservice elementary teachers' beliefs about science teaching. Journal of Science Teacher Education, 19(2), 183-204.

Young, T. (1998). Student teachers' attitudes towards science (STATS). Evaluation and Research in Education, 12(2), 96-111.

Zhang, D. and Campbell, T. (2010). The Psychometric evaluation of a three-dimension elementary science attitude survey. Journal of Science Teacher Education, 22, 595-612. 